\title{
Treatment patterns of high-dose-rate and low-dose-rate brachytherapy as monotherapy for prostate cancer
}

\author{
Justin Barnes, BS MS*, William R Kennedy, MD²*, Benjamin W Fischer-Valuck, MD MS³, Brian C Baumann, MD², \\ Jeff M Michalski, MD², Hiram A Gay, MD² \\ ISaint Louis University School of Medicine, Saint Lovis, MO 63104, United States, ²Department of Radiation Oncology, Washington University \\ School of Medicine, Saint Lovis, MO 63110, United States, ${ }^{3}$ Department of Radiation Oncology. Emory University School of Medicine, Atlanta. \\ GA 30307, United States \\ *Justin Barnes and William R Kennedy contributed equally to this work.
}

\begin{abstract}
Purpose: Monotherapy with high-dose-rate (HDR) or low-dose-rate (LDR) brachytherapy are both recommended modalities for prostate cancer. The choice between HDR and LDR is dependent on patient, physician, and hospital preferences. We sought to identify treatment patterns and factors associated with receipt of HDR or LDR monotherapy.

Material and methods: We queried the National Cancer Database (NCDB) for patients with localized low- or intermediate-risk prostate cancer treated with HDR or LDR monotherapy. Descriptive statistics were used to analyze patterns of HDR vs. LDR. Patient characteristics were correlated with HDR vs. LDR using multivariable logistic regression.

Results: We identified 50,326 patients from 2004-2014: LDR 37,863 (75.2\%) vs. HDR 12,463 (24.8\%). Median follow-up was 70.3 months. The overall use of monotherapy declined over time. HDR application declined relative to LDR. In 2004, 27.0\% of cases were HDR compared to 19.2\% in 2014. Factors associated with increased likelihood of HDR on multivariable analysis included: increasing age (OR: 1.01, 95\% CI: 1.01-1.01), cT2c disease (OR: 1.25, 95\% CI: 1.11-1.41), treatment at an academic center (OR: 2.45, 95\% CI: 2.24-2.65), non-white race (OR: 1.34, 95\% CI: 1.27-1.42), and income $>\$ 63,000$ (OR: 1.73, 95\% CI: 1.59-1.88). LDR was more common in 2010-2014 (OR: 0.59, 95\% CI: 0.540.65), Charlson-Deyo comorbidity index $>0$ (OR: 0.89, 95\% CI: 0.84-0.95), and for patients receiving hormone therapy (OR: 0.88, 95\% CI: 0.83-0.93). No difference in prostate-specific antigen (PSA) or Gleason score and receipt of HDR vs. LDR was observed. Mean overall survival was 127.0 months for HDR and 125.4 for LDR, and was not statistically different.

Conclusions: We observed an overall decrease in brachytherapy (BT) monotherapy use since 2004 for localized prostate cancer. Despite similar survival outcomes, the use of HDR monotherapy declined relative to LDR.

J Contemp Brachytherapy 2019; 11, 4: 320-328 DOI: https://doi.org/10.5114/jcb.2019.86974
\end{abstract}

Key words: prostate cancer, brachytherapy, monotherapy, HDR, LDR, NCDB.

\section{Purpose}

Prostate cancer causes significant morbidity and is the second most common cause of cancer-specific mortality in men in the United States [1]. In the era of prostate-specific antigen (PSA) testing, patients are frequently diagnosed with localized, low- and intermediate-risk disease [2,3]. Management options include radical prostatectomy (RP), external beam radiotherapy (EBRT), brachytherapy (BT), or active surveillance (AS). Despite an overall decline in the use of BT alone or as a boost in combination with EBRT since the early 2000s, monotherapy using either high-dose-rate (HDR) or low-dose-rate (LDR) brachytherapy remains one of the most cost-effective options for pa- tients with localized prostate cancer compared to other modalities $[4,5,6,7]$.

Monotherapy with either HDR or LDR brachytherapy both represents efficacious, high-value options for treating localized prostate cancer. However, no prospective, randomized data are currently available comparing these two methods in either the context of monotherapy or as a boost to EBRT. Adopted into clinical practice first, the collective LDR experience includes more patients with greater follow-up duration compared with $\operatorname{HDR}[8,9,10]$. However, initial institutional outcomes with HDR monotherapy suggest encouraging rates of disease control, potentially improved urethral and rectal dosimetry, and favorable acute toxicity profiles $[11,12,13,14,15,16]$. 
Consequently, the choice between HDR vs. LDR is likely dependent on a variety of factors, including patient characteristics, physician expertise, and treatment facility preference, although data informing these decisions are sparse. We therefore sought to determine treatment patterns, clinical outcomes, and patient factors influencing the choice between LDR and HDR monotherapy in a modern cohort of patients with low- and intermediate-risk prostate cancer using a large hospital-based registry, the National Cancer Database (NCDB).

\section{Material and methods}

We queried the 2014 participant user files of the NCDB for patients with prostate cancer diagnosed in 2004-2014, treated with brachytherapy as their sole method of radiation therapy. NCDB is a joint program of the American College of Surgeons and the American Cancer Society that provides data available on patients diagnosed at Commission on Cancer (CoC) accredited cancer centers, capturing approximately $70 \%$ of all newly-diagnosed cancer annually in the United States [17]. All variables used in the analysis are described in the participant user files (PUF) data dictionary version 2014, and any derivations are outlined in the tables. We included patients with localized low- or intermediate-risk prostate cancer, specifically those with stage $\leq \mathrm{cT} 2 \mathrm{c}$, Gleason score $\leq 7$, and/or PSA $<20$. We excluded patients who received external beam radiation or RP and patients who had node-positive or high-risk prostate cancer. We included patients who receive hormone therapy [10].

Descriptive statistics were applied to analyze patterns of use of HDR compared to LDR. Relationships between HDR vs. LDR use and patient demographics and disease characteristics (race/ethnicity, age, year of diagnosis, PSA, Gleason score, insurance, T stage, facility type and location, urban/rural/metro residence, Charlson-Deyo comorbidity index, hormone therapy receipt, zip-code level income, and education) were assessed using multivariable logistic regression. Equality of HDR vs. LDR use by covariates with more than 2 levels was assessed using the multivariable Wald test.

Survival among HDR and LDR recipients was assessed using Kaplan-Meier curves, log-rank tests, and Cox proportional hazards regression. To account for potential selection bias in the HDR and LDR groups, we included the aforementioned covariates in the proportional hazards model and performed Kaplan-Meier and log-rank tests with inverse probability weights (IPW) derived from the predicted values of a multivariable logistic regression model with the same set of covariates. The success of covariate balance was evaluated by standardized mean differences and kernel density plots.

Adequacy of the proportional hazards' assumption was formally tested comparing Schoenfeld residuals against transformed time, and covariates with non-proportional hazards were removed and instead used as strata. Analyses were performed in R 3.3.2 using the survival and IPW survival packages, and figures were generated using the ggplot2, lattice, and latticeExtra packages.
All $p$-values were 2 -sided if applicable, and $p<0.05$ was considered statistically significant.

\section{Results}

We identified 37,863 LDR and 12,463 HDR recipients who met the aforementioned inclusion and exclusion criteria. Patient characteristics are reported in Table 1. Median follow-up was 70.3 (range, 0-143.2). Overall, the application of BT monotherapy decreased over the study period, with HDR monotherapy use declining relative to LDR (Figure 1). In 2004, 27.0\% of monotherapy cases were HDR compared to $19.2 \%$ in 2014 (odds ratio [OR] 0.60, $p<0.001$ ).

On multivariable analysis (Table 2), black patients were more likely to receive HDR than whites (OR: 1.181, 95\% CI: 1.113-1.253, $p<0.001)$. Receipt of HDR varied significantly by age ( $p$-value for difference $=0.028)$, where older patients were more likely to receive HDR (OR of HDR receipt relative to patients < 50 years: 0.944 for $50-59,1.033$ for $60-69$ years, 1.041 for $70-79$ years, and 1.125 for $>80$ years). Those diagnosed after 2010 were less likely to receive HDR than those diagnosed earlier (OR: 0.546, 95\% CI: 0.498-0.599, $p<0.001)$. Patients with stage cT2b disease were less likely to receive HDR (OR: 0.842, 95\% CI: $0.734-0.965, p=0.013$ ), whereas patients with stage cT2c disease were more likely to receive HDR (OR: 1.188, 95\% CI: 1.055-1.339, $p=0.005$ ) relative to those with cT1c (reference) or cT2a disease. Receipt of HDR treatment was more likely in an academic facility (OR: 1.684, $95 \%$ CI: $1.605-1.766, p<0.001)$ relative to a non-academic facility. Metropolitan residents were more likely than rural (reference) and urban residents to receive HDR (OR: 1.36, 95\% CI: 1.142-1.618, $p=0.001)$. Relative to those with a Charlson-Deyo comorbidity index of 0 , those with an index of 1 were less likely to receive HDR (OR: 0.929, 95\% CI: 0.868-0.994, $p=0.032$ ). Recipients of hormone therapy were less likely to receive HDR than non-recipients (OR: 0.917, 95\% CI: 0.869-0.968, $p=0.002$ ). Receipt of HDR varied significantly by income ( $p$-value for difference $<0.001)$ and education ( $p$-value for difference $<0.001$ ), where residents of the highest-earning (OR: 1.074) or most highly-educated (OR: 1.208) zip-codes were more likely to receive HDR than those in lower-earning (mid-low, specifically) and less-educated (low, specifically) zip-codes. Receipt of HDR also varied significantly by region $(p<0.001)$.

The survival curves for HDR and LDR recipients are given in Figure 2A. Overall survival (OS) at 5- and 10 -years was $92.9 \%$ and $75.3 \%$ for LDR and $93.9 \%$ and $76.6 \%$ for HDR, respectively, with HDR recipients having significantly better survival $(p<0.001)$. After IPW adjustment to account for potential selection bias (see Figures 3 and 4$)$, the difference was non-significant $(p=0.252)$, with estimated 5- and 10 -year OS of $93.1 \%$ and $75.9 \%$ for LDR and $93.2 \%$ and $74.2 \%$ for HDR, respectively (Figure $2 B$ ). In the proportional hazard regression analysis, the receipt of HDR vs. LDR was not significantly associated with survival (HR: 0.82, 95\% CI: 0.28-2.406, $p=0.718$ ). Furthermore, there were no patient or disease characteristics that had varied survival based on the type of brachytherapy received $(p>0.062)$. 
Table 1. Patient and treatment related characteristics

\begin{tabular}{|c|c|c|c|}
\hline & All patients $(n=50,326)$ & $\operatorname{LDR}(n=37,863)$ & $\operatorname{HDR}(n=12,463)$ \\
\hline \multicolumn{4}{|l|}{ Race } \\
\hline White & $42,518(84.5)$ & $32,263(85.2)$ & $10,255(82.3)$ \\
\hline Black & $7,808(15.5)$ & $5,600(14.8)$ & $2,208(17.7)$ \\
\hline \multicolumn{4}{|l|}{ Age (years) } \\
\hline Median (range) & $66(29-90)$ & $66(29-90)$ & $66(38-90)$ \\
\hline$<50$ & $828(1.6)$ & $609(1.6)$ & $219(1.8)$ \\
\hline $50-59$ & 9,871 (19.6) & 7,411 (19.6) & 2,460 (19.7) \\
\hline $60-69$ & $22,862(45.4)$ & $17,134(45.3)$ & $5,728(46.0)$ \\
\hline 70-79 & $15,605(31.0)$ & $11,846(31.3)$ & $3,759(30.2)$ \\
\hline$\geq 80$ & $1,160(2.3)$ & $863(2.3)$ & $297(2.4)$ \\
\hline \multicolumn{4}{|l|}{ Year } \\
\hline 2004-2009 & $33,925(67.4)$ & $24,666(65.1)$ & $9,259(74.3)$ \\
\hline 2010-2014 & $16,401(32.6)$ & $13,197(34.9)$ & $3,204(25.7)$ \\
\hline \multicolumn{4}{|l|}{ PSA } \\
\hline$<10$ & 46,123 (91.6) & $34,623(91.4)$ & $11,500(92.3)$ \\
\hline $10-20$ & $4,203(8.4)$ & $3,240(8.6)$ & $963(7.7)$ \\
\hline \multicolumn{4}{|l|}{ Gleason score } \\
\hline 6 & 24,109 (47.9) & $17,494(46.2)$ & $6,615(53.1)$ \\
\hline 7 & $6,860(13.6)$ & $5,054(13.3)$ & $1,806(14.5)$ \\
\hline Unknown & $19,357(38.5)$ & $15,315(40.4)$ & 4,042 (32.4) \\
\hline \multicolumn{4}{|l|}{ Insurance } \\
\hline Private & $22,341(44.4)$ & $16,465(43.5)$ & $5,876(47.1)$ \\
\hline Uninsured & $309(0.6)$ & $241(0.6)$ & $68(0.5)$ \\
\hline Government & $27,160(54.0)$ & 20,807 (55.0) & $6,353(51.0)$ \\
\hline Unknown & $516(1.0)$ & $350(0.9)$ & $166(1.3)$ \\
\hline \multicolumn{4}{|l|}{ T stage } \\
\hline $1 \mathrm{C}$ & $39,955(79.4)$ & $30,077(79.4)$ & $9,878(79.3)$ \\
\hline $2 \mathrm{~A}$ & 6,361 (12.6) & 4,752 (12.6) & 1,609 (12.9) \\
\hline $2 \mathrm{~B}$ & $1,361(2.7)$ & $1,065(2.8)$ & $296(2.4)$ \\
\hline $2 \mathrm{C}$ & $1,544(3.1)$ & $1,113(2.9)$ & $431(3.5)$ \\
\hline 2 NOS & $1,105(2.2)$ & $856(2.3)$ & $249(2.0)$ \\
\hline \multicolumn{4}{|l|}{ Facility type } \\
\hline Non-academic & $36,853(73.2)$ & 28,835 (76.2) & $8,018(64.3)$ \\
\hline Academic & $13,467(26.8)$ & $9,024(23.8)$ & 4,443 (35.6) \\
\hline Unspecified & $6(0)$ & $4(0)$ & $2(0)$ \\
\hline \multicolumn{4}{|l|}{ Residence } \\
\hline Rural & $1,303(2.6)$ & $1,140(3.0)$ & $163(1.3)$ \\
\hline Urban & $8,702(17.3)$ & $7,219(19.1)$ & $1,483(11.9)$ \\
\hline Metro & $39,286(78.1)$ & $28,686(75.8)$ & $10,600(85.1)$ \\
\hline Unspecified & $1,035(2.1)$ & $818(2.2)$ & $217(1.7)$ \\
\hline \multicolumn{4}{|l|}{ Charlson-Deyo } \\
\hline$\underline{0}$ & $43,321(86.1)$ & $32,351(85.4)$ & $10,970(88)$ \\
\hline 1 & $6,086(12.1)$ & 4,774 (12.6) & $1,312(10.5)$ \\
\hline$>1$ & 919 (1.8) & 738 (1.9) & $181(1.5)$ \\
\hline \multicolumn{4}{|l|}{ Hormone therapy } \\
\hline None & $38,128(75.8)$ & $28,471(75.2)$ & $9,657(77.5)$ \\
\hline Yes & $10,610(21.1)$ & $8,206(21.7)$ & 2,404 (19.3) \\
\hline Unknown & $1,588(3.2)$ & $1,186(3.1)$ & $402(3.2)$ \\
\hline
\end{tabular}


Table 1. Cont.

\begin{tabular}{|c|c|c|c|}
\hline & All patients $(n=50,326)$ & $\operatorname{LDR}(n=37,863)$ & $\operatorname{HDR}(n=12,463)$ \\
\hline \multicolumn{4}{|l|}{ Income } \\
\hline Low & 7,738 (15.4) & $6,186(16.3)$ & $1,552(12.5)$ \\
\hline Mid-low & $11,916(23.7)$ & $9,452(25.0)$ & 2,464 (19.8) \\
\hline Mid-high & $13,055(25.9)$ & $9,862(26.0)$ & $3,193(25.6)$ \\
\hline High & $17,617(35.0)$ & $12,363(32.7)$ & $5,254(42.2)$ \\
\hline \multicolumn{4}{|l|}{ Education } \\
\hline Low & 6,718 (13.3) & $5,305(14.0)$ & $1,413(11.3)$ \\
\hline Mid-low & $12,363(24.6)$ & $9,444(24.9)$ & 2,919 (23.4) \\
\hline Mid-high & $17,519(34.8)$ & $13,290(35.1)$ & $4,229(33.9)$ \\
\hline High & $13,726(27.3)$ & $9,824(25.9)$ & $3,902(31.3)$ \\
\hline \multicolumn{4}{|l|}{ Facility location } \\
\hline New England & $3,482(6.9)$ & 2,791 (7.4) & $691(5.5)$ \\
\hline Middle Atlantic & $7,285(14.5)$ & $4,937(13.0)$ & 2,348 (18.8) \\
\hline South Atlantic & $12,218(24.3)$ & $9,044(23.9)$ & $3,174(25.5)$ \\
\hline East North Central & $9,307(18.5)$ & 6,949 (18.4) & 2,358 (18.9) \\
\hline East South Central & $4,251(8.4)$ & 3,835 (10.1) & $416(3.3)$ \\
\hline West North Central & 4,032 (8.0) & $3,576(9.4)$ & $456(3.7)$ \\
\hline West South Central & $2,068(4.1)$ & $1,765(4.7)$ & $303(2.4)$ \\
\hline Mountain & $1,800(3.6)$ & $1,606(4.2)$ & $194(1.6)$ \\
\hline Pacific & $5,877(11.7)$ & $3,356(8.9)$ & $2,521(20.2)$ \\
\hline Unspecified & $6(0)$ & $4(0)$ & $2(0)$ \\
\hline
\end{tabular}

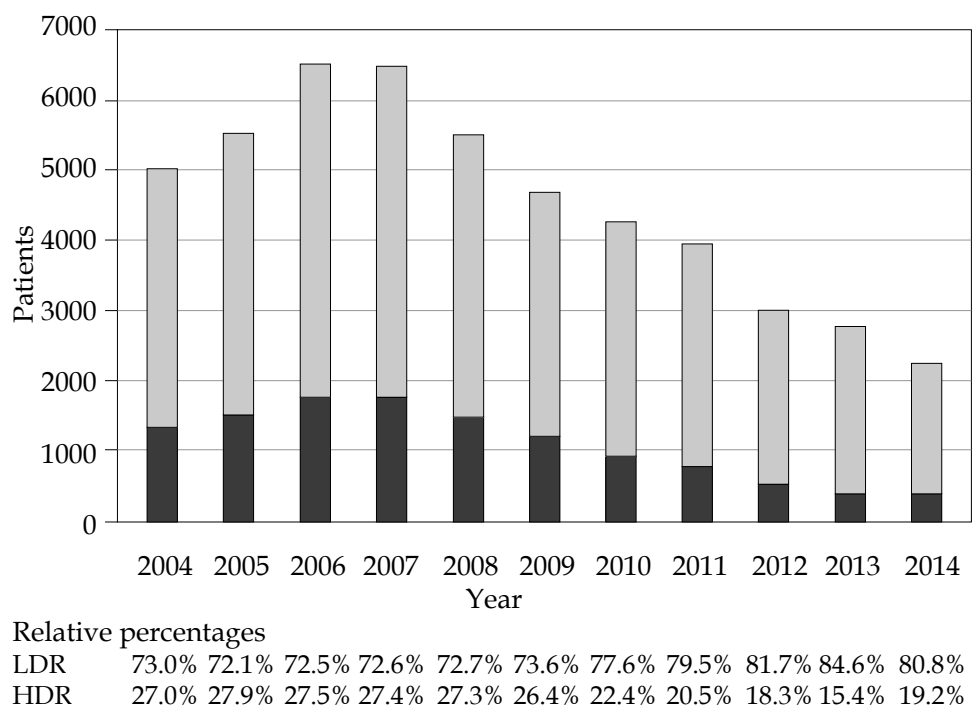

घ HDR $\square \mathrm{LDR}$

Fig. 1. Trends of HDR and LDR brachytherapy utilization from 2004 to 2014

\section{Discussion}

Our study of this large patient cohort reveals that the overall use of brachytherapy as monotherapy for lowand intermediate-risk prostate cancer has been steadily declining in recent years. We found that relative to LDR, the proportion of patients treated with HDR monotherapy exhibited an overall decline as well. We found that the receipt of HDR vs. LDR monotherapy differs significant- ly by nearly every patient factor, sociodemographic, and disease-specific. Our work identified that HDR monotherapy was more likely in patients who were black, were older, and lived in zip-codes associated with higher income and education; in patients who had fewer comorbidities, had stage cT2c disease, and had not received hormone therapy; and in patients treated in academic facilities, facilities in metropolitan areas, or facilities in coastal or Northeastern locations. Furthermore, our results sug- 
Table 2. Multivariable logistic regression analysis of association between HDR vs. LDR and patient characteristic

\begin{tabular}{|c|c|c|c|c|c|}
\hline Covariate & Estimate & & & $P$-value & $\begin{array}{c}P \text {-value } \\
\text { for difference }\end{array}$ \\
\hline (Intercept) & 0.141 & 0.109 & 0.183 & $<0.001$ & \\
\hline \multicolumn{6}{|l|}{ Race } \\
\hline White & Reference & Reference & Reference & Reference & \multirow[t]{2}{*}{$<0.001$} \\
\hline Black & 1.181 & 1.113 & 1.253 & $<0.001$ & \\
\hline \multicolumn{6}{|l|}{ Age } \\
\hline$<50$ & Reference & Reference & Reference & Reference & \multirow[t]{5}{*}{0.028} \\
\hline $50-59$ & 0.944 & 0.798 & 1.117 & 0.501 & \\
\hline $60-69$ & 1.033 & 0.876 & 1.219 & 0.7 & \\
\hline $70-79$ & 1.041 & 0.878 & 1.234 & 0.648 & \\
\hline$\geq 80$ & 1.125 & 0.905 & 1.397 & 0.29 & \\
\hline \multicolumn{6}{|l|}{ Year } \\
\hline 2004-2009 & Reference & Reference & Reference & Reference & \multirow[t]{2}{*}{$<0.001$} \\
\hline 2010-2014 & 0.546 & 0.498 & 0.599 & $<0.001$ & \\
\hline \multicolumn{6}{|l|}{ PSA } \\
\hline$<10$ & Reference & Reference & Reference & Reference & \multirow[t]{2}{*}{0.249} \\
\hline $10-20$ & 0.955 & 0.882 & 1.033 & 0.248 & \\
\hline \multicolumn{6}{|l|}{ Gleason } \\
\hline 6 & Reference & Reference & Reference & Reference & \multirow[t]{3}{*}{$<0.001$} \\
\hline 7 & 0.969 & 0.909 & 1.033 & 0.333 & \\
\hline Unknown & 1.189 & 1.088 & 1.299 & $<0.001$ & \\
\hline \multicolumn{6}{|l|}{ Insurance } \\
\hline Private & Reference & Reference & Reference & Reference & \multirow[t]{4}{*}{0.001} \\
\hline Uninsured & 0.866 & 0.654 & 1.147 & 0.315 & \\
\hline Government & 0.97 & 0.922 & 1.021 & 0.245 & \\
\hline Unknown & 1.415 & 1.161 & 1.723 & 0.001 & \\
\hline \multicolumn{6}{|l|}{ T stage } \\
\hline $1 \mathrm{C}$ & Reference & Reference & Reference & Reference & \multirow[t]{5}{*}{$<0.001$} \\
\hline $2 \mathrm{~A}$ & 1.024 & 0.961 & 1.092 & 0.462 & \\
\hline $2 \mathrm{~B}$ & 0.842 & 0.734 & 0.965 & 0.013 & \\
\hline $2 C$ & 1.188 & 1.055 & 1.339 & 0.005 & \\
\hline 2 NOS & 0.878 & 0.756 & 1.018 & 0.085 & \\
\hline \multicolumn{6}{|l|}{ Facility type } \\
\hline Non-academic & Reference & Reference & Reference & Reference & \multirow[t]{3}{*}{$<0.001$} \\
\hline Academic & 1.684 & 1.605 & 1.766 & $<0.001$ & \\
\hline Unspecified & 2.766 & 0.493 & 15.509 & 0.247 & \\
\hline \multicolumn{6}{|l|}{ Residence } \\
\hline Rural & Reference & Reference & Reference & Reference & \multirow[t]{4}{*}{$<0.001$} \\
\hline Urban & 1.056 & 0.883 & 1.264 & 0.548 & \\
\hline Metro & 1.36 & 1.142 & 1.618 & 0.001 & \\
\hline Unspecified & 0.95 & 0.753 & 1.199 & 0.666 & \\
\hline \multicolumn{6}{|l|}{ Charlson-Deyo } \\
\hline$\underline{0}$ & Reference & Reference & Reference & Reference & \multirow[t]{3}{*}{0.023} \\
\hline 1 & 0.929 & 0.868 & 0.994 & 0.032 & \\
\hline$>1$ & 0.853 & 0.72 & 1.011 & 0.067 & \\
\hline \multicolumn{6}{|l|}{ Hormone therapy } \\
\hline None & Reference & Reference & Reference & Reference & \multirow[t]{3}{*}{0.007} \\
\hline Yes & 0.917 & 0.869 & 0.968 & 0.002 & \\
\hline Unknown & 0.985 & 0.873 & 1.112 & 0.807 & \\
\hline
\end{tabular}


Table 2. Cont.

\begin{tabular}{|c|c|c|c|c|c|}
\hline Covariate & Estimate & & & $P$-value & $\begin{array}{c}P \text {-value } \\
\text { for difference }\end{array}$ \\
\hline \multicolumn{6}{|l|}{ Income } \\
\hline Low & Reference & Reference & Reference & Reference & \multirow[t]{4}{*}{$<0.001$} \\
\hline Mid-low & 0.928 & 0.858 & 1.005 & 0.066 & \\
\hline Mid-high & 1.024 & 0.943 & 1.111 & 0.571 & \\
\hline High & 1.074 & 0.982 & 1.175 & 0.12 & \\
\hline \multicolumn{6}{|l|}{ Education } \\
\hline Low & Reference & Reference & Reference & Reference & \multirow[t]{4}{*}{$<0.001$} \\
\hline Mid-low & 1.154 & 1.066 & 1.249 & $<0.001$ & \\
\hline Mid-high & 1.051 & 0.967 & 1.143 & 0.244 & \\
\hline High & 1.208 & 1.101 & 1.326 & $<0.001$ & \\
\hline \multicolumn{6}{|l|}{ Facility location } \\
\hline New England & Reference & Reference & Reference & Reference & \multirow[t]{10}{*}{$<0.001$} \\
\hline Middle Atlantic & 1.892 & 1.714 & 2.089 & $<0.001$ & \\
\hline South Atlantic & 1.693 & 1.538 & 1.864 & $<0.001$ & \\
\hline East North Central & 1.638 & 1.483 & 1.809 & $<0.001$ & \\
\hline East South Central & 0.58 & 0.506 & 0.664 & $<0.001$ & \\
\hline West North Central & 0.677 & 0.593 & 0.773 & $<0.001$ & \\
\hline West South Central & 0.915 & 0.787 & 1.065 & 0.251 & \\
\hline Mountain & 0.633 & 0.532 & 0.752 & $<0.001$ & \\
\hline Pacific & 3.575 & 3.232 & 3.953 & $<0.001$ & \\
\hline Unspecified & NA & NA & NA & NA & \\
\hline
\end{tabular}

A

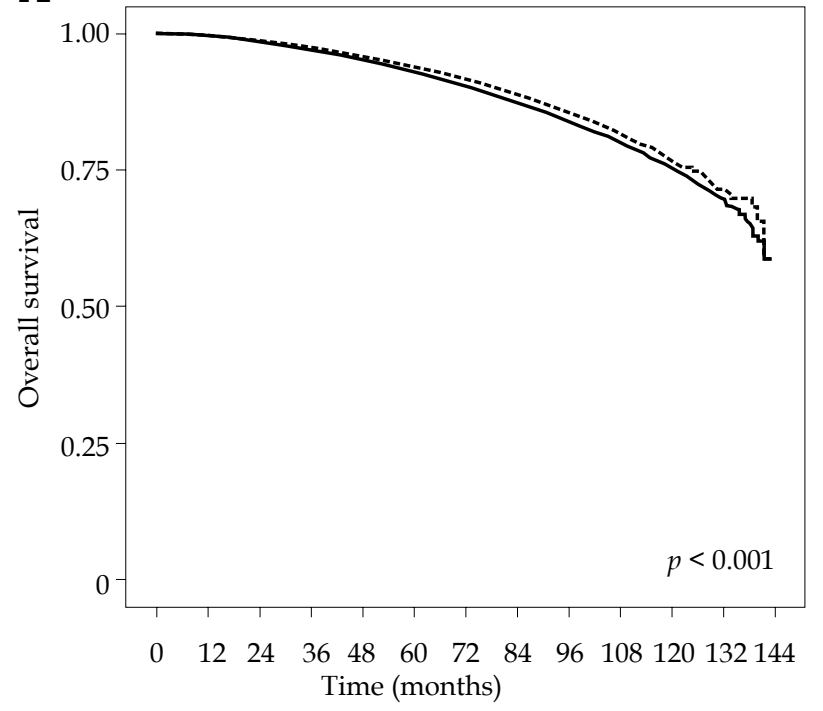

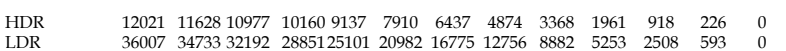

- LDR
B

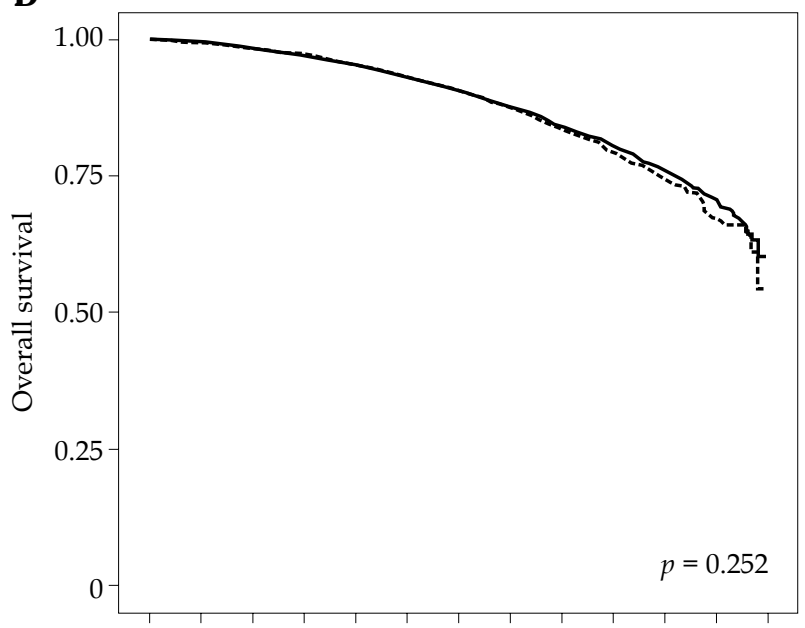

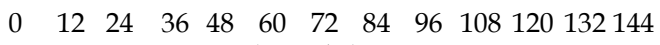
Time (months)

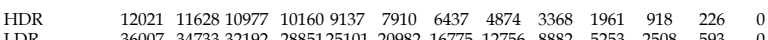
LDR -... HDR

Fig. 2. Survival in HDR vs. LDR recipients, unadjusted (A) and IPW-adjusted (B)

gest that the overall survival is similar for patients treated with HDR and LDR brachytherapy.

An overall decline in brachytherapy for prostate cancer, both as a boost with EBRT and as monotherapy, has been previously reported, both within the percent of patients receiving any form of radiotherapy, declining from $45 \%$ to $38 \%$ from 2005 to 2009 , and as a percent of those receiving any definitive therapy, declining from $17 \%$ to $8 \%$ from the peak year of 2002 to $2010[18,19]$. Furthermore, the percent of brachytherapy monotherapy among all types of prostate cancer management strategies, including those without definitive treatment, has declined from $12.1 \%$ in 2004 to $4.6 \%$ in 2014 , with stable trends in EBRT (22.5\% in 2004 to $23.4 \%$ in 2014) and 
A

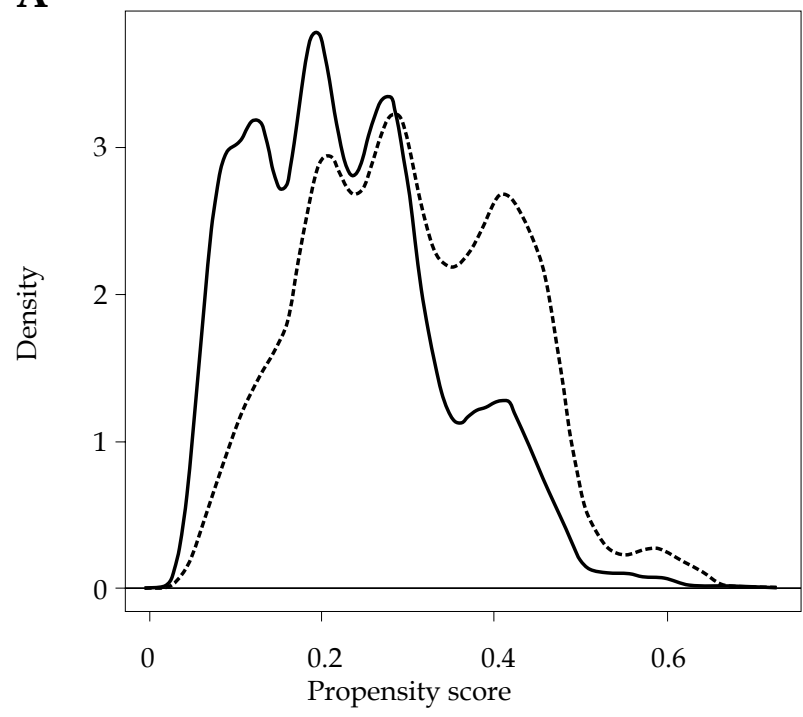

B

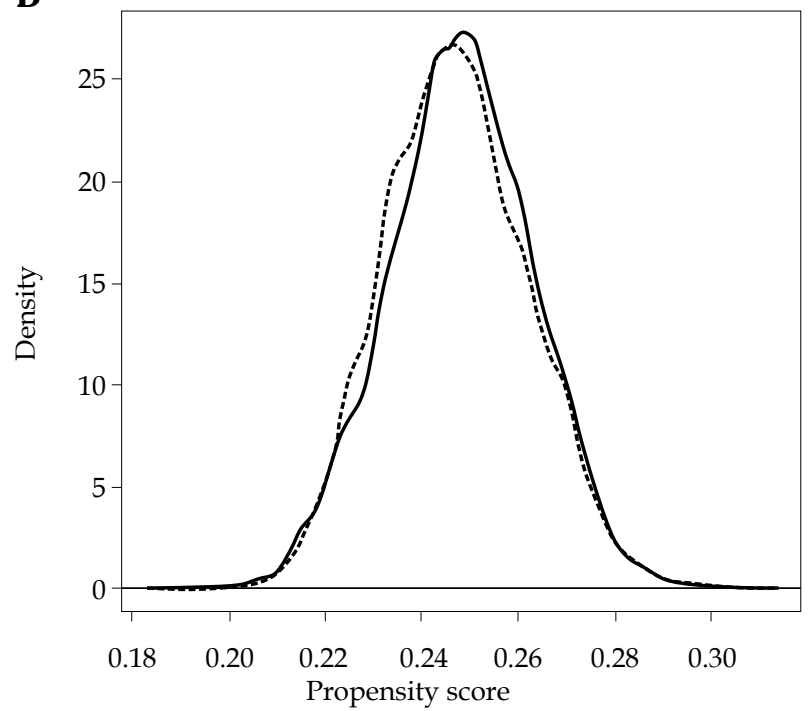

LDR $\quad-\cdots \cdot$ HDR

Fig. 3. Kernel density plot of propensity scores generated from model before (A) and after (B) IPW adjustment

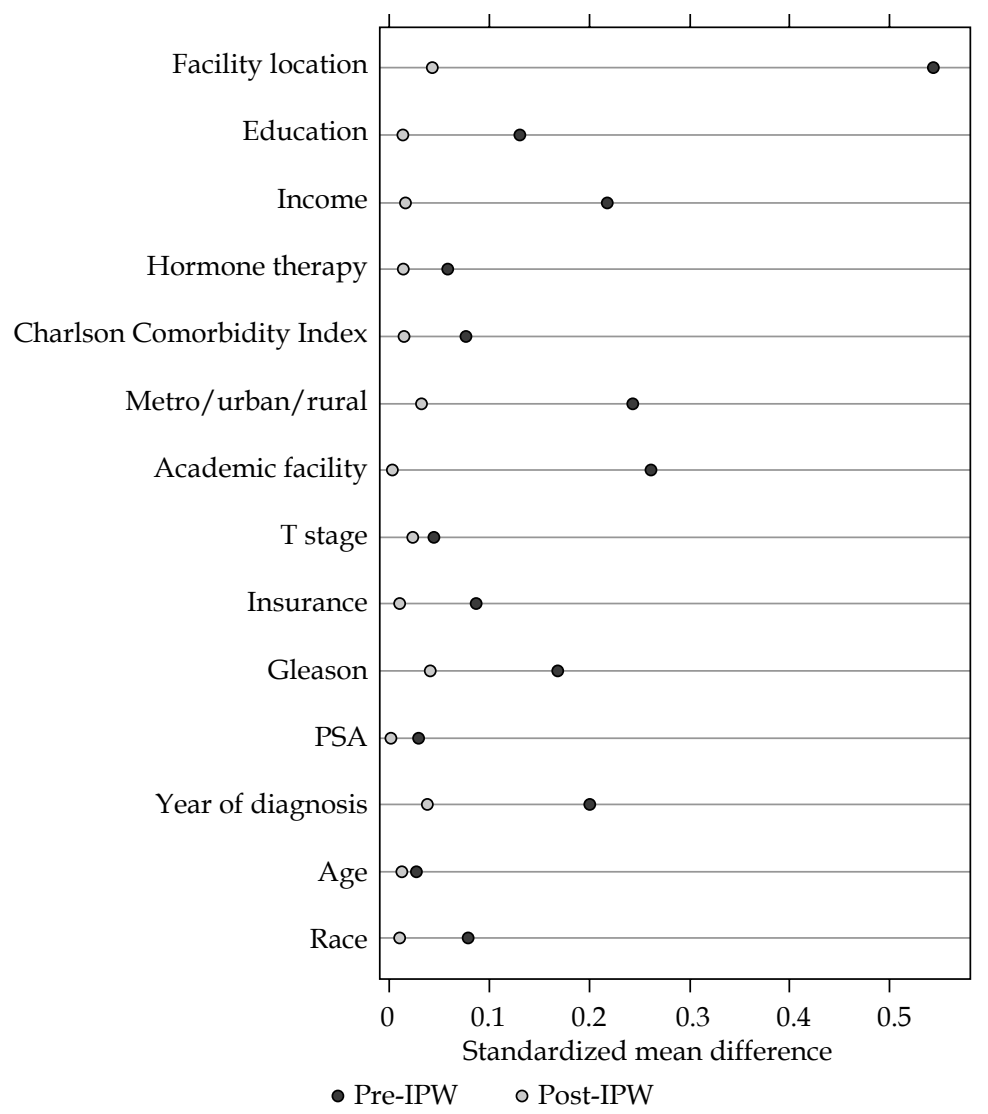

Fig. 4. Covariate standardized mean differences before and after IPW adjustment

further decreases in EBRT + BT $(5.3 \%$ in 2004 to $3.4 \%$ in 2014) [20]. These decreasing rates of brachytherapy are attributable to several factors, such as the increased adoption of newer technologies like stereotactic body radiotherapy, maturing data for moderately-hypofrac- tionated EBRT, reimbursement incentives, and reduced physician training in brachytherapy. For instance, increases in the use of IMRT and robotic surgeries have coincided with a decline in the number of brachytherapy cases $[21,22,23,24]$. 
Regarding newer technologies, Martin and colleagues identified the peak year of prostate brachytherapy use to be 2002 before a general decline, directly preceded by the first report of robot-assisted laparoscopic prostatectomy and FDA approval of CyberKnife for prostate cancer, both in 2001 [19]. Finally, the exposure to brachytherapy procedures has been reportedly declining in resident training programs, decreasing the pool of experienced brachytherapists who are willing to perform the procedure $[25,26]$.

Observing that rates of brachytherapy are decreasing is surprising, as brachytherapy for low- to intermediate-risk prostate cancer has been demonstrated to have equivalent or superior outcomes relative to other options and is thought to be to be the least costly active treatment option $[4,27,28,29]$. In one analysis, median cost of SBRT was $\$ 27,145$ compared to $\$ 17,183$ for brachytherapy, $\$ 37,090$ for IMRT, and $\$ 54,706$ for proton beam therapy $(p<0.001)$. However, another study did suggest that SBRT might be slightly more cost effective than LDR brachytherapy [30,31].

Our findings that HDR monotherapy use is decreasing relative to LDR are also surprising, given the potential radiobiological advantages of HDR, and encouraging disease control and quality-of-life outcomes to date $[11,12,13,14,15,16,32]$. One explanation may be that HDR may be less convenient to the patient, since LDR typically involves a single outpatient procedure, whereas HDR often requires multiple implants and potential hospital admission; however, further maturation of outcomes data for single-fraction HDR may mitigate these differences [12]. The price of HDR may also compare favorably relative to LDR. It has been suggested that single-fraction HDR monotherapy is least expensive $(\$ 9,850)$, followed by laparoscopic surgery $(\$ 11,098)$, then open radical prostatectomy $(\$ 13,829)$, and LDR brachytherapy $(\$ 13,893)$, with combined EBRT and BT being the most expensive $(\$ 18,819)$; however, another study suggested that HDR may become more expensive than LDR $(\$ 6,869)$, with increasing fractions (single fraction: \$5,582; multifraction: \$9,538) [33,34]. Interestingly, the use of HDR brachytherapy has been shown to be increasing in Europe, contrary to the findings of our current study in a large, United States-based cohort [35]. No randomized controlled trials comparing LDR and HDR BT as monotherapy have been conducted, though outcomes of the two appear similar upon synthesis of the available data [36]. Our retrospective study also found no differences in survival between the two modalities, which is unsurprising, given the low- and intermediate-risk patients included in this analysis.

Despite the strengths of our study, it is affected by several limitations inherent to its design. As this is a retrospective database analysis, our results may be biased or inaccurate due to selection bias, incomplete data, and coding errors. Furthermore, since the NCDB only includes hospitals that are $\mathrm{CoC}$ accredited, which tend to be larger and in urban locations with more cancer-related services, we may underrepresent patients who are referred directly for outpatient therapy at non-hospital sites, thus potentially omitting a disproportionate num- ber of patients receiving RT. Furthermore, while we utilized inverse probability weights to address this, a direct comparison of the efficacy of LDR and HDR is difficult due to the retrospective nature of the project, and thus no causal inference can be made. The NCDB includes records from many facilities, and the observations from these facilities may be non-independent; however, a regression model with robust standard errors to account for potential correlation among observations gave virtually identical results (data not shown). Finally, the outcome comparison in this analysis is limited, as the NCDB only reports overall survival information, so we were unable to compare biochemical control and locoregional or distant failure, which may be more useful metrics for lowand intermediate-risk prostate cancer.

\section{Conclusions}

We observed an overall decline in the use of brachytherapy monotherapy for the treatment of lowand intermediate-risk prostate cancer. While HDR and LDR monotherapies were associated with comparable long-term survival outcomes, the use of HDR significantly decreased relative to LDR. Furthermore, several patient characteristics were predictive for receipt of HDR versus LDR monotherapy.

\section{Acknowledgements}

The Authors wish to acknowledge the Commission on Cancer of the American College of Surgeons and the American Cancer Society for making public data available through the National Cancer Data Base (NCDB). The NCDB is a joint project of the Commission on Cancer $(\mathrm{CoC})$ of the American College of Surgeons and the American Cancer Society. The CoC's NCDB and the hospitals participating in the CoC NCDB are the source of the de-identified data used herein; they have not verified and are not responsible for the statistical validity of the data analysis or the conclusions derived by the authors.

\section{Disclosure}

Authors report no conflict of interest.

\section{References}

1. Siegel RL, Miller KD, Jemal A. Cancer statistics, 2018. CA Cancer J Clin 2018; 68: 7-30.

2. Shen X, Kumar P. Trade-off between treatment of early prostate cancer and incidence of advanced prostate cancer in the prostate screening era. J Urol 2016; 195: 1397-1402.

3. Bokhorst LP, Zappa M, Carlsson SV et al. Correlation between stage shift and differences in mortality in the European Randomized study of Screening for Prostate Cancer (ERSPC). BJU Int 2016; 118: 677-680.

4. Shah C, Lanni TB, Ghilezan MI et al. Brachytherapy provides comparable outcomes and improved cost-effectiveness in the treatment of low/intermediate prostate cancer. Brachytherapy 2012; 11: 441-445.

5. Amin NP, Sher DJ, Konski AA. Systematic review of the cost effectiveness of radiation therapy for prostate cancer from 2003 to 2013. Appl Health Econ Health Policy 2014; 12: 391-408. 
6. Becerra V, Ávila M, Jimenez J et al. Economic evaluation of treatments for patients with localized prostate cancer in Europe: a systematic review. BMC Health Serv Res 2016; 16: 541.

7. Muralidhar V, Nguyen PL. Maximizing resources in the local treatment of prostate cancer: A summary of cost-effectiveness studies. Urol Oncol 2017; 35: 76-85.

8. Fellin G, Mirri MA, Santoro L et al. Low dose rate brachytherapy (LDR-BT) as monotherapy for early stage prostate cancer in Italy: practice and outcome analysis in a series of 2237 patients from 11 institutions. Br J Radiol 2016; 89: 20150981.

9. Kittel JA, Reddy CA, Smith KL et al. Long-term efficacy and toxicity of low-dose-rate $125 \mathrm{i}$ prostate brachytherapy as monotherapy in low-, intermediate-, and high-risk prostate cancer. Int J Radiat Oncol 2015; 92: 884-893.

10. Routman DM, Funk RK, Stish BJ et al. Permanent prostate brachytherapy monotherapy with I-125 for low- and intermediate-risk prostate cancer: Outcomes in 974 patients. Brachytherapy 2019; 18: 1-7.

11. Hoskin P, Rojas A, Ostler P et al. High-dose-rate brachytherapy with two or three fractions as monotherapy in the treatment of locally advanced prostate cancer. Radiother Oncol 2014; 112: 63-67.

12. Prada PJ, Ferri M, Cardenal J et al. High-dose-rate interstitial brachytherapy as monotherapy in one fraction of $20.5 \mathrm{~Gy}$ for the treatment of localized prostate cancer: Toxicity and 6-year biochemical results. Brachytherapy 2018; 17: 845-851.

13. Morton G, Chung HT, McGuffin M, et al. Prostate high doserate brachytherapy as monotherapy for low and intermediate risk prostate cancer: Early toxicity and quality-of life results from a randomized phase II clinical trial of one fraction of 19 Gy or two fractions of 13.5Gy. Radiother Oncol 2017; 122: 87-92.

14. Major T, Polgár C, Jorgo $\mathrm{K}$ et al. Dosimetric comparison between treatment plans of patients treated with low-doserate vs. high-dose-rate interstitial prostate brachytherapy as monotherapy: Initial findings of a randomized clinical trial. Brachytherapy 2017; 16: 608-615.

15. Hauswald H, Kamrava MR, Fallon JM et al. High-dose-rate monotherapy for localized prostate cancer: 10-year results. Int J Radiat Oncol 2016; 94: 667-674.

16. Yamazaki H, Masui K, Suzuki G et al. High-dose-rate brachytherapy monotherapy versus low-dose-rate brachytherapy with or without external beam radiotherapy for clinically localized prostate cancer. Radiother Oncol 2019; 132: 162-170.

17. Newman LA, Lee CT, Parekh LP et al. Use of the National Cancer Data Base to develop clinical trials accrual targets that are appropriate for minority ethnicity patients: a report from the American College of Surgeons Oncology Group (ACOSOG) Special Population Committee. Cancer 2006; 106: 188-195.

18. Mahmood U, Pugh T, Frank S et al. Declining use of brachytherapy for the treatment of prostate cancer. Brachytherapy 2014; 13: 157-162.

19. Martin JM, Handorf EA, Kutikov A et al. The rise and fall of prostate brachytherapy: use of brachytherapy for the treatment of localized prostate cancer in the National Cancer Data Base. Cancer 2014; 120: 2114-2121.

20. Burt LM, Shrieve DC, Tward JD. Factors influencing prostate cancer patterns of care: An analysis of treatment variation using the SEER database. Adv Radiat Oncol 2018; 3: 170-180.

21. Jacobs BL, Zhang Y, Schroeck FR et al. Use of advanced treatment technologies among men at low risk of dying from prostate cancer. JAMA 2013; 309: 2587-2595.

22. Stitzenberg KB, Wong Y-N, Nielsen ME et al. Trends in radical prostatectomy: centralization, robotics, and access to urologic cancer care. Cancer 2012; 118: 54-62.
23. Lowrance WT, Eastham JA, Savage C et al. Contemporary open and robotic radical prostatectomy practice patterns among urologists in the United States. J Urol 2012; 187: 20872092.

24. Barbash GI, Glied SA. New technology and health care costs - the case of robot-assisted surgery. N Engl J Med 2010; 363: 701-704.

25. Amini A, Jones BL, Jackson MW et al. Survival outcomes of combined external beam radiotherapy and brachytherapy vs. brachytherapy alone for intermediate-risk prostate cancer patients using the National Cancer Data Base. Brachytherapy 2016; 15: 136-146.

26. Compton JJ, Gaspar LE, Shrieve DC et al. Resident-reported brachytherapy experience in ACGME-accredited radiation oncology training programs. Brachytherapy 2013; 12: 622-627.

27. Wilson LS, Tesoro R, Elkin EP et al. Cumulative cost pattern comparison of prostate cancer treatments. Cancer 2007; 109: 518-527.

28. Hayes JH, Ollendorf DA, Pearson SD et al. Observation versus initial treatment for men with localized, low-risk prostate cancer: a cost-effectiveness analysis. Ann Intern Med 2013; 158: $853-860$

29. Grimm P, Billiet I, Bostwick D et al. Comparative analysis of prostate-specific antigen free survival outcomes for patients with low, intermediate and high risk prostate cancer treatment by radical therapy. Results from the Prostate Cancer Results Study Group. BJU Int 2012; 109 Suppl 1: 22-29.

30. Halpern JA, Sedrakyan A, Hsu WC et al. Utilization, complications, and costs of stereotactic body radiation therapy (SBRT) for localized prostate cancer. Cancer 2016; 122: 24962504.

31. Helou JA, Torres S, Musunuru HB et al. Low dose rate brachytherapy vs standard external beam radiotherapy vs. stereotactic body radiotherapy for low risk prostate cancer: A cost-utility analysis. J Clin Oncol 2016; 34: 6628-6628.

32. King CR. LDR vs. HDR brachytherapy for localized prostate cancer: the view from radiobiological models. Brachytherapy 2002; 1: 219-226.

33. Ilg AM, Laviana AA, Kamrava $M$ et al. Time-driven activity-based costing of low-dose-rate and high-dose-rate brachytherapy for low-risk prostate cancer. Brachytherapy 2016; 15: 760-767.

34. Larrea L, Muñoz EL, Antonini P et al. Treatment cost comparison for radical prostatectomy, volumetric arc therapy (VMAT) with high-dose-rate brachytherapy (HDR) boost, HDR monotherapy single fraction and I-125 implant for localized prostate cancer in a Spanish private practice. Brachytherapy 2015; 14: S38-S39.

35. Guedea F, Venselaar J, Hoskin P et al. Patterns of care for brachytherapy in Europe: Updated results. Radiother Oncol 2010; 97: 514-520.

36. Zaorsky NG, Shaikh T, Murphy CT et al. Comparison of outcomes and toxicities among radiation therapy treatment options for prostate cancer. Cancer Treat Rev 2016; 48: 50-60. 